year so pending a re-application, the emphasis is now on establishing firmer links with three computing centres in the universities (among them being the centre at the Czech Technical University which has the IBM 3090 supplied in 1991 under IBM's Academic Initiative). The difficulty to establish a feepaying clientele for a supercomputing centre is demonstrated by the fact that the country's weather services prefer to carry out much of their computing abroad at something like five-times the cost.

\section{HUNGARY}

Hungary's work in advanced computing was traditionally carried out at the Computation and Automation Institute of the Hungarian Academy of Sciences in Budapest. The main change occurred when Budapest's University of Economic Sciences acquired an IBM 3090 under IBM's Academic Initiative for its Budapest University Computing Centre on the condition that an academic network was built up (this is being done under the national Information Infrastructure Develop- ment Programme). There has has been a tendency to concentrate resources at the workstation level as it is acknowledged that this level cannot be ignored. A true supercomputing level of the Cray or Convex class is missing and there appears to be no definite plans to change this. Computational physicists therefore tend to work abroad, with some questioning whether this is particularly cost-effective.

P.G. Boswell

\title{
NEUTRON SCATTERING
}

\section{Representatives Opt for a Federation}

The various national organizations representing users of neutron sources have set up a representative body of delegates called the European Neutron Scattering Representation committee. It met for the first time on 5 September in Grenoble and elected D. Richter from the KFA Jülich as the interim chairman. The committee's main task is to decide upon and implement the best form for future representation for Europe's neutron scattering community. Various options were discussed and following a vote it was agreed to aim for a federative structure whereby national organizations would nominate delegates. However, the advantages of a representative society to which Europe's neutron scatterers could belong were clearly recognized, so it was also decided to aim in the long term at forming a European society.

Norbert Kroó, the EPS President, argued vigorously for an EPS Interdivisional Group as this would provide a solid legal framework strong links to other organizations, full representation of members, close involvement in established conferences and publications, and low secretariat costs. The major difficulty seems to be that EPS largely represents physicists while neutron scattering involves scientists from other fields (some $35 \%$ of Europe's 1400 neutron scatterers are che- mists and $10 \%$ are biologists). However, R. Scherm, the ILL's Associate Director who becomes the Director on 1 November (replacing J. Charvolin who was Director during the refurbishment of the ILL's reactor), feels that physicists often play a key role since they must increasingly make neutron easily available to users with a variety of backgrounds and interests. So it is not unreasonable for physicists to take the lead. Second, the Interdivisional Group concept has shown in the case of computing and control systems that it can cater very successfully for the multidisciplinary aspects of science while providing the advantages of full representation.

A task force composed of F. Barrochi (Florence University), C. Carlile (RutherfordAppleton Laboratory), A. Furrer (PSI, Villigen), D. Richter (KFA, Jülich), and T. Tasset (ILL, Grenoble) was formed to draft statutes for a new organization. The committee itself will next meet on 11-12 December in Madrid.

\section{NATIONAL ORGANIZATIONS}

National organizations for neutron scattering exist in Germany and Russia (committees), the UK (joint IOP/Royal Society of Chemistry group), and Italy and Switzerland (societies). There are plans to form a society in France, a society-based group in Austria, and an organization in Spain.

\section{Full Professorship}

The Technical University of Denmark (DTU) invites applications for a full professorship associated Mikroelektronik Centret (MIC) in condensed matter opto-electronics.

The professor shall strenghten MIC's R\&D programme within advanced semiconductor materials and their application in opto-electronic components and devices. Nonlinear ultrafast dynamics is of interest for optical switching as is the development of new technologies for the realisation of nanostructures for electronics, optics and mechanics. The successful candidate should document a profound knowledge of modern low-dimensional materials and their optical properties.

The professor is expected to contribute to the dynamical research environment at MIC and DTU. In addition to excellent professional skills, the professorship will therefore require flexibility and an ability to outline competitive research goals of relevance to external partners from industry and academia. Within DTU, MIC is responsible for educating students in semiconductor process technology and microand nanotechnology. The professor will be responsible for supervising PhD students and giving graduate as well as advanced undergraduate lectures.

For further information, contact Director Ove Poulsen, Tel. +4545934610 or Rector Hans Peter Jensen, Tel. +45 4588 2222. Applications should be sent to: Rector, Technical University of Denmark, Bldg. 101A. DK-2800 Lyngby, Denmark, before Nov. 10th. The successful candidate is selected by an expert committee refering to the Rector of DTU. Applicants will receive the results of the final expert evaluation. The evaluation will, however, not be published without approval of all applicants.

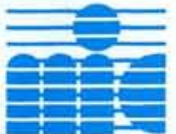

\section{MikroelekTRONIK Centret}

MIC is a new research centre at the Technical University of Denmark. Our research focuses on semiconductor-based technologies. Strong emphasis is on microsystems encompassing full integration between integrated optics, micro-and nanotechnology, and electronics. Major Danish industries work together at MIC. Our new process laboratory is in full operation and in addition MIC has established state-of-the-art photonics laboratories, including a new fs-laboratory.

\section{Main Issues Identified}

The discussions to form a new organization to represent Europe's neutron scattering community come at a time when several international bodies are taking a fairly close look at future requirements. It is therefore perhaps natural that the community itself feels it needs to speak with a more coherent voice. Participants at the EPS Large Facilities in Physics Conference in Lausanne (12. 14 September) heard of evaluations by the OECD Megascience Forum (its report will be published later this year) and by the European Union of Physics Research Organizations (EURPRO). UNESCO's Physics Advisory Council is making a general overview of facilities, the European Science Foundation is planning to examine neutron requirements, while the European Commission monitors neutron users fairly closely in the context of its Access to Large Installations initiative (which will continue in the 4th Framework programme 1994-98). The main issues are: - The extent to which large facilities such as the ILL reactor source and the RutherfordAppleton Laboratory's ISIS spallation source should be further developed. There is clear evidence that their full potential is unrealized and that any increase in support to allow increased access to neutrons would be used very efficiently as a relatively small proportion would need to be spent on fixed costs.

- The extent to which small, essentially national, centres should be involved in training specialists coming from many fields, improving detectors, and upgrading facilities.

- The importance attached to a major, new international source such as the proposed European Spallation Source providing a qualitative advance in performance that will take 10-20 years to realize.

\section{ESRF INAUGURATED}

The European Synchrotron Radiation Facility (ESRF) was inaugurated on 30 September by representatives of the 12 contracting partners and over 400 guests. J. Fillon, France's Minister for Higher Education and Research, with negotiations to settle the additional host-state contributions to CERN's LHC project in mind, referred to the ESRF as well adapted to constructing a "scientific Europe" because it exemplified an approach that was not too formalised.

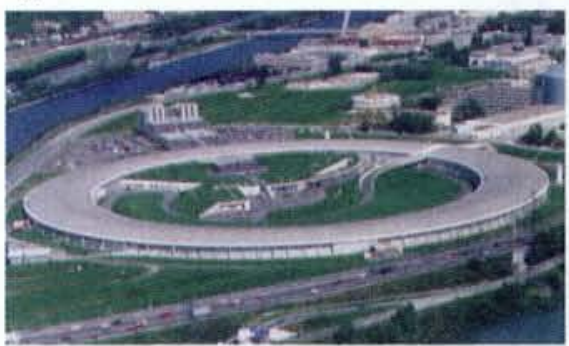

